\title{
Going Multimodal: What is a Mode of Arguing and Why Does it Matter?
}

\author{
Leo Groarke
}

Published online: 17 October 2014

(C) The Author(s) 2014. This article is published with open access at Springerlink.com

\begin{abstract}
During the last decade, one source of debate in argumentation theory has been the notion that there are different modes of arguing that need to be distinguished when analyzing and evaluating arguments. Visual argument is often cited as a paradigm example. This paper discusses the ways in which it and modes of arguing that invoke non-verbal sounds, smells, tactile sensations, music and other non-verbal entities may be defined and conceptualized. Though some attempts to construct a 'multimodal' theory of argument are criticized, it advocates for an argumentation theory that makes room for visual arguing and for other non-verbal modes that have not been explored in depth. In the process, the paper provides a method for identifying the structure of multimodal arguments and argues that adding modes to our theoretical tool box is an important step toward a comprehensive account of argument.
\end{abstract}

Keywords Visual argument - Multimodality - Modes of arguing · Gilbert . Argument by smell · Argument by experience $\cdot$ Dressing arguments

\section{Introduction}

In theoretical discussions of argument, it is increasingly common to distinguish between different 'modes' of arguing. In some cases, this tendency is rooted in the work of Gilbert and those he has influenced (see, e.g., Gilbert, 1994, 1997, 2002, 2004; Duran 2007, 2010; Carozza 2007; Langsdorf 2003). They adopt an argument

\footnotetext{
L. Groarke $(\bowtie)$

Trent University, Peterborough, ON K9J 7B8, Canada

e-mail: leogroarke@trentu.ca

L. Groarke

Centre for Research on Reasoning, Argumentation and Rhetoric, University of Windsor, Windsor, ON N9B 3P4, Canada
} 
typology that distinguishes between four different modes of arguing. Three of these modes contradict the norms associated with the 'critical logical' mode emphasized in traditional studies of argument. In other cases, commentators have invoked modes of arguing (and 'multimodal' argument) to explain the non-verbal elements that play a role in many acts of arguing. The significance of these elements is highlighted in the work of a growing number of authors who recognize that there are ways of arguing which employ pictures or other visual components (see, e.g., Tseronis 2013; Birdsell and Groarke 2007; Blair 1996; Dove 2012; Groarke 1996; van den Hoven 2012; Kjeldsen 2007; Feteris et al. 2011; Roque 2012; Slade 2002).

Other potential modes of arguing match the modes of communication emphasized in social semiotics. It maintains that elements of design, illustration, typography, etc. function as non-verbal ways of supporting and advocating different points of view (Kress and Van Leeuwen 1996; Kress 2010; Iedema 2003). Within argumentation theory, Groarke and Dewey (2002) have identified a musical mode of arguing in which music plays a crucial role. Gelang and Kjeldsen (2011) have identified a potential actio mode in the facial expressions, gestures, posture, tone of voice and other aspects of nonverbal personal communication (aspects of an arguer's actio) that can play a key role in acts of arguing. As the latter write: "The now famous "Dean Scream" is an example of this: During the US 2004 primaries, Howard Dean (D) spoke at a rally in Iowa, finishing a section of the speech with a screaming "Yeah!!", supported by a huge swing of his arm. This outburst caused the speech-and hence Howard Dean - to be framed as loud, peculiar, and unpresidential.... Such behavior may be read by the audience as an argument suggesting that a candidate is not fit to be president." (571)

Discussions of possible modes raise questions about modes of argument which merit more attention than they have so far received. In this essay, I want to address some of them by developing an account of modes which allows us to apply standard theories of argumentation (pragma-dialectics, informal logic, rhetoric, dialogue theory, etc.) to acts of arguing that employ non-verbal modes of argument. In doing so, I aim to expand the realm of argumentation theory to arguing that depends, not only on visual images, but on sounds, tastes, music, smells, tactile sensations and other non-verbal phenomena that arguers often use in their attempts to provide support for their conclusions. In the course of my discussion, I try to (1) demonstrate that there are acts of arguing of this sort; (2) provide a method for analyzing (in particular, 'dressing') the acts of arguing in question; (3) develop a general account of modes that can be applied to them; and (4) show that my way of defining modes overcomes some of the issues that arise with alternative accounts. My fundamental goal is a demonstration that modes of arguing can be a useful addition to the toolbox we utilize when we attempt to analyze acts of arguing.

\section{Acts of Arguing, Dressed and Undressed}

I define an argument as a standpoint (a conclusion) backed by reasons (premises) offered in support of it. In a typical case of arguing, arguments are an attempt to resolve disagreement (sometimes understood as argument $_{2}$-O'Keefe 1977), 
though they may also function as an attempt to avoid disagreement by securely establishing some belief. I will understand an act of arguing as an attempt to use premises and conclusions to resolve some disagreement or potential disagreement. 'Argumentation' includes not only arguments, but also the broader dialogue, discussion and disagreement in which arguments are embedded. Acts of arguing attempt to rationally establish some conclusion by providing evidence in its favour. Exactly what counts as 'rational' in this context is a complex and controversial question which lies beyond the scope of the present paper. For our purposes, it will suffice to say that the premises of a strong argument are acceptable and provide significant evidence in support of the argument's conclusion.

Following Pinto (2001), I understand acts of arguing and argument in a way that is broader than classical logic. The latter takes the premises and conclusion of an argument to be propositions (claims about what is true) that are expressed in words. In contrast, Pinto understands an argument as "an invitation to inference" (68-69) that may involve premises and conclusions which are not clearly propositional. In the present essay, I want to move in a similar direction. The kinds of examples that motivate me are acts of arguing that involve pictures, maps, sounds, diagrams, smells, video clips, and other non-verbal phenomena which are not propositional in the way that verbal statements are (though it bears noting that the relationship between sentences and propositions is itself a matter of much controversy).

In analyzing acts of arguing and the arguments they forward, one of the first tasks we face is the identification of an argument's premises and conclusions. Doing so is sometimes called 'dressing' (or 'standardizing') the argument (see Woods 1995). In some cases, the structure of an argument is so obvious that dressing it raises no significant concerns. In the textbook example, "All men are mortal, Socrates is a man, so Socrates is mortal," it is obvious that the first two clauses of the sentence serve as the argument's premises and the last as its conclusion. Dressing an argument is a more complex matter when we are faced with many real life arguments, for their premises and conclusions may be unclear or open to debate. Identifying them may require that we decide how to deal with digressions; with rewordings of (roughly) the same claim; with implicit (or 'hidden') premises or conclusions; with rhetorical questions and other rhetorical devices; and with incomplete, vague or ambiguous claims and utterances.

I propose to deal with the issues dressing raises by using what I will call a 'Key Component' (KC) table and a corresponding diagram to clarify the content and structure of the argument proposed in a particular act of arguing. The $\mathrm{KC}$ table does its work by isolating the key components of the act of arguing; by identifying the premises and conclusions they forward; and by providing some kind of rationale for interpreting them in the way we do. In the case of the argument: 'Socrates is a man, so Socrates is mortal', we can dress this act of arguing with the following $\mathrm{KC}$ table. 


\begin{tabular}{lll}
\hline Act of arguing & Argument & Mode of arguing \\
\hline Claim that 'Socrates is a man' & Premise $(s)$ : Socrates is a man & Verbal claim \\
& Premise $(a)$ : All men are mortal & Enthymeme \\
Claim that 'Socrates is mortal' & Conclusion $(m):$ Socrates is mortal & Verbal claim
\end{tabular}

s+a

In this table, an act of arguing is analyzed as an act made up of two component acts: i.e. the two instances of claiming identified in the top and bottom boxes of the left hand column. The middle column identifies the elements of the argument that correspond to these components. There is no component of the act of arguing that corresponds to the second premise (hence the second box in the left hand column is empty) because it is an implicit premise. The third column in the table identifies the components of the act of arguing as instances of a particular "mode" (a way) of arguing. I have treated enthymematic reasoning as a mode of arguing that is distinct from arguing that is accomplished by way of explicit verbal claims. The third column in the $\mathrm{KC}$ table is probably unnecessary in a case as obvious as this one, but will be a key consideration in the attempt to understand more complex acts of arguing. Having labeled the premises and conclusions of the proposed argument in our $\mathrm{KC}$ table, the attached diagram illustrates its structure.

A KC table can be used to summarize the meaning of a verbal argument, but I have different interests here. In a discussion of multimodal argument, I want to use $\mathrm{KC}$ tables as a tool for dressing multimodal acts of arguing. When used in this way, such tables can be seen as a variant of the tables van den Hoven (2012) has used in his analysis of complex examples of multimodal argument. His tables are an attempt to identify and distinguish key segments of multi-modal arguments. The tables I propose attempt to do the same, but in a way that more clearly identifies the premise-conclusion structure of such arguments, and is independent of the complex theory of argument he proposes. The latter (e.g., its account of mimesis and diegesis) is worth comment in its own right, but it lies beyond the scope of the present essay.

I will illustrate the multimodal use of a $\mathrm{KC}$ table with a simple example. Imagine that we are standing in line at the Amsterdam airport, Schiphol, having debated the question whether the foremost proponent of pragma-dialectics, Frans van Eemeren, is in Brazil. I have adamantly maintained that he is still in Amsterdam, and you have disagreed. In the wake of our unresolved disagreement, I happen to see him standing in a line in front of us. In attempting to settle our disagreement silently, I open a book and display a photo of van Eemeren, nudge you with my elbow, and point at the elegantly dressed man a few meters in front of us, raising my eyebrows as I do. You look and nod resignedly when I ask you 'Was I right?'

It should be clear that my actions in this situation are a clear act of arguing: I am trying to resolve a disagreement by providing evidence for a conclusion. When we analyze my reasoning we can dress the argument I devise with the following $\mathrm{KC}$ table. 


\begin{tabular}{lll}
\hline Act of arguing & Argument & Mode of arguing \\
\hline $\begin{array}{l}\text { Display of the photograph } \\
\begin{array}{l}\text { Directing your attention to the } \\
\text { man in front of us }\end{array}\end{array}$ & $\begin{array}{c}\text { Premise }(p) \text { : photograph }(l) \text { : what we see } \\
\text { Asking 'Was I right?' }\end{array}$ & $\begin{array}{c}\text { Visual (facial expression, } \\
\text { pointing, observation) }\end{array}$ \\
& Conclusion $(r)$ : I was right (Van & Rhetorical question \\
& Eemeren is in Amsterdam). & \\
\hline
\end{tabular}

$p+l$

Our table recognizes my display of a photograph and our observation of the man standing in line in front of us as key acts of looking subsumed in my act of arguing. In the proposed analysis of the argument, they are identified as key premises. The third line of our table identifies a conclusion which is conveyed by the posing of a rhetorical question. In the diagram that accompanies the table, the formula $p+l$ identifies the comparison of these two acts of seeing as the basis of the conclusion that van Eemeren is here, in Amsterdam (and I was right about this). In the third column of our table, these acts of looking are identified as instances of the 'visual' mode of arguing.

In constructing $\mathrm{KC}$ tables for real acts of arguing, many complexities are possible. A verbal premise or conclusion may be presented, not as a single sentence, but as a paragraph or an extended description. In case of a photograph, an act of arguing may depend, not on the display of an entire photograph but on the display of a particular detail it includes (as when we identify someone by pointing to a feature of their face as it is depicted in a mug shot). In such a case it may be this detail which is best identified as a key component of the argument. In identifying a visual premise or conclusion it may be important to recognize that it is, more specifically, a particular mode of visual arguing. Recognizing an image as a cartoon implies, for example, that it needs to be interpreted in a different way than a drawing which purports to show what someone or something actually looks like. The best $\mathrm{KC}$ table is the one that best prepares the way for a discussion and evaluation of the act of arguing in question.

A second example can illustrate one complexity which is particularly important in a multimodal context. In this case, imagine that we are at a wine tasting for California wine. Someone tells you that Frog's Leap PS 2013 is magnificent. When you respond with a doubtful look, she tells you that the magazine Food \& Wine ranked it the best Petite Syrah of the year, then pours a glass and says 'here's the proof.' This is a case in which our host is forwarding an argument, offering you reasons why you should accept her point of view. One of the reasons-perhaps the deciding one-is the tasting of the wine in question, which is supposed to provide evidence for her standpoint. In this case, we may dress her argument as follows. 


\begin{tabular}{lll}
\hline Act of arguing & Argument & Mode of arguing \\
\hline Claim that 'Frog's Leap PS 2013 & Conclusion $(m)$ : Frog's Leap PS & Verbal claim \\
is magnificent' & 2013 is magnificent & \\
Claim that 'Food and Wine rates & Premise $(f)$ : Food and Wine rates & Verbal claim \\
it the best Petite Syrah this year' & it the best Petite Syrah this year & \\
The tasting of the wine & Premise $(t)$ : Taste experience & Arguing by taste
\end{tabular}

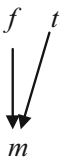

In this case, the act of arguing begins with the claim that becomes the argument's conclusion, making this the first component in the arguer's act of arguing. When she is required to defend this view she provides two strands of inference that converge on the conclusion $m$. In the $\mathrm{KC}$ table, the second $(t)$ has been identified as an instance of a mode of arguing from taste. Though this is a mode of arguing that is ignored in standard accounts of argument it is a decisive mode in this context. In an extended debate about varieties of Petite Syrah, conclusions may turn on a whole series of tastings involving many different vintages.

$\mathrm{KC}$ tables allow us to dress multimodal arguments in a way that recognizes the non-verbal components of an act of arguing as premises and conclusions. One might contrast this way of dressing multimodal acts of arguing with attempts to understand them as a means of forwarding arguments which are collections of propositions which can in some way be verbally expressed (cf. Groarke 1996; Blair 1996; Barceló Aspeitia 2012). Adopting the latter approach, one dresses and analyzes an argument that employs non-verbal elements by dressing and analyzing its verbal counterpart.

This is not the place to compare these two ways of dealing with non-verbal argument in detail, but I want to note two general considerations that favour the $\mathrm{KC}$ method I am using here. First and foremost, $\mathrm{KC}$ tables provide a more faithful account of what actually occurs in many multimodal acts of arguing: for these are acts in which an arguer uses non-verbal elements to establish a conclusion without some attempt to convert them into verbal counterparts. In our van Eemeren example, I don't proceed by translating the photograph I show you into words. I just show you the photograph. In deciding whether you will accept my conclusion you don't consider some verbal counterpart-you just compare the photograph and the man in front of us (and then assent). Your eyes and brain do the work without relying on words. In our second example, your tasting of Frog's Leap PS 2013 may convince you that it is magnificent. In some cases, an attempt to verbally describe the taste may help further the critical discussion, but there are many cases in which such disagreements are resolved without any need of verbal elaboration. Even in the 
former cases, it is tasting, not words, that take precedence (as the old adage puts it, 'the proof of the pudding is the tasting').

By recognizing non-verbal elements of acts of arguing as premises and conclusions, $\mathrm{KC}$ tables eliminate many of the issues of interpretation that arise when we attempt to understand non-verbal modes of arguing in terms of verbal counterparts. In the case of tastes and scents, it is notoriously difficult to find precise verbal counterparts of non-verbal entities. In the case of photographs and maps, non-verbal elements provide more information than we can adequately capture in a reasonably sized set of sentences. In the case of the van Eemeren photo, we would have to describe the shape and length and colour of the eyes, the chin, the nose, the hair, the neck, and an enormous number of other details. To complicate matters further, different verbal descriptions of non-verbal entities are usually possible, making it difficult to choose between them. All of this makes the attempt to convert (to 'translate') non-verbal components into equivalent sentences inherently problematic. Using $\mathrm{KC}$ tables as I have eliminates the need to do so.

In proposing $\mathrm{KC}$ tables, I am not suggesting that the analysis of non-verbal elements in multimodal acts of arguing never requires a verbal discussion. Like verbal premises and conclusions, such elements may be vague, ambiguous, contentious, unclear or in some other way difficult to understand. In such situations, verbal discussion may be the best (or at least a crucial) way to resolve the questions that this raises. This is one of the reasons that many acts of arguing are inherently multimodal, for what is presented in one mode may often be clarified by appeal to another. In the case of non-verbal arguing, it can still be said that many non-verbal elements of argument are self-sufficient and do not require a verbal rendering. When they do, verbal discussion does not replace these elements so much as it aids us in our attempt to understand them. In other cases, clarification moves in the other direction when we use non-verbal modes to explicate a verbal text, as when we draw a diagram to help us better understand a written argument.

If one's method for analyzing multimodal arguments proceeds by summarizing non-verbal elements verbally, then the problems that arise when one attempts intermodal translations arise when one analyzes any instance of multimodal argument. When one uses KC tables, such issues arise only when one's account of an argument's multimodal components is in some manner contentious. In our van Eemeren example, this renders unnecessary an inherently contentious inquiry into the difficult question how one might verbally capture what the photograph of van Eemeren displays or what we see when we look at the man in front of us. We can simply point to these multimodal components. In other cases where someone doubts some multimodal component (by arguing that it does not show what we think, for example), then we may have to grapple with a verbal discussion of this component and what it entails. The important point is that the $\mathrm{KC}$ approach does not make this a part of every instance of analysis.

A particular $\mathrm{KC}$ table can be understood as one attempt to interpret an act of arguing. In the case of non-verbal modes it is a more modest attempt at interpretation than the attempt to turn non-verbal elements into verbal counterparts, but it is still an interpretation. Like all interpretations, this means that it is inherently open to criticism and dispute. One of the reasons for using a $\mathrm{KC}$ table is to outline 
an interpretation of an act of arguing in a way that invites scrutiny, criticism, and debate. To fully appreciate how this can help us understand an argument, something more needs to be said about the modes it may identify.

\section{What is a Mode of Arguing?}

The classical model of argument understands arguments to be entities made up of words and sentences. In using other modes of arguing, arguers build arguments from other kinds of ingredients - pictures, diagrams, non-verbal sounds, tastes, and so on. With this in mind, I will define modes in terms of the ingredients (the 'material', the 'stuff') an arguer uses and arranges when they engage in an act of arguing. One might roughly compare the distinction between different modes of arguing to a distinction between different modes of building which defines the the latter in terms of the ingredients (concrete, stone, bricks, wood, etc.) builders use. In the case of arguing, this way of defining modes suggests that an arguer who uses words employs a verbal mode of arguing; that an arguer who constructs an argument with images uses a visual mode of arguing; that an arguer who uses taste as a component of their argument uses a mode of arguing by taste; and so on and so forth. A theory that recognizes these different modes (and the ways they combine and mix in many real life arguments) is a multimodal theory.

This general account of modes might be described as a 'material' or 'constructivist' account in the sense that it defines modes in terms of the material arguers use to construct acts of arguing. There is a sense in which a written argument is constructed of letters or, even more fundamentally, the ink spots or pixels that letters are made of, but these are not (at least in ordinary cases of arguing) the building blocks that are our focus on when we argue. In the case of verbal arguing, words and sentences are the semantically significant components we assemble to create an act of arguing. In the case of pictures and other non-verbal elements, we may similarly say that it is semantically relevant elements that are the ingredients that matter, and that it is these that define a mode.

In comparison with traditional theories, a multimodal theory of argument significantly expands what is semantically significant when we consider argument. How far this should be expanded will have to be decided through surveys of actual multimodal arguments but we can illustrate this with our previous examples. In the van Eemeren example, I create an argument from a photograph, a shared observation, and a rhetorical question. In the second, your server constructs an argument (an attempt to resolve disagreement by providing evidence) from verbal claims and a tasting. In the first case my arguing employs visual and verbal modes of arguing. In the second, the server employs verbal claims and tastes as modes of arguing.

Consider a new example. We are in India, driving from Chennai to Vellore. We disagree on the directions so we stop the car and look at a map. You point to relevant aspects of the map and argue, in a sequence of steps, that we should take a 
series of roads and turns along highways 205,58 , and 126 . In the process you offer a series of multimodal arguments that have the following general structure.

\begin{tabular}{llc}
\hline Act of arguing & Argument & Mode of arguing \\
\hline Pointing out a detail of the map & $\begin{array}{c}\text { Premise }(m) \text { : Detail in } \\
\text { question }\end{array}$ & $\begin{array}{c}\text { Visual (arguing } \\
\text { 'cartographically') }\end{array}$ \\
$\begin{array}{l}\text { Claim that 'We should drive in this direction } \\
\text { [on this highway, etc.]' }\end{array}$ & $\begin{array}{c}\text { Conclusion }(d) \text { : We should } \\
\text { drive in this direction. }\end{array}$ & \begin{tabular}{c} 
Verbal claim \\
\hline
\end{tabular} \\
\hline
\end{tabular}

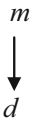

Your full argument includes a sequence of sub arguments that uses of details on the map $\left(m_{1}, m_{2}, m_{3}, m_{4}, m_{5}\right.$, etc.) to establish a series of directions $\left(d_{1}, d_{2}, d_{3}, d_{4}, d_{5}\right.$, etc.) that will take us to Vellore. Your extended act of arguing may include verbal arguments that address the question how we should interpret our map and whether it is reliable. To that extent, your act of arguing may invoke a verbal mode of arguing, but it is also multimodal, for it employs a visual mode of arguing (arguing 'cartographically') which makes the depictions of roads on our map an essential ingredient of your argument which must be considered in a full attempt to analyze it.

Consider one more example. Two friends, Frank and Ernie, spot a large group of swans on the Detroit River in December. Frank says that they must be mute swansbecause this is a breed that is displacing the trumpeter swans indigenous to the region (so much so that conservationists have taken measures to prevent this). Ernie disagrees. He argues that the swans must be trumpeters on migration, because this is the place where trumpeter swans migrate in December. We decide we will resolve the debate: we put a canoe in the water, paddle to the swans and record their songs. Later we compare our recordings to the recordings of swan songs we find in the sound library of the Cornell Ornithology lab. A day later we play all the recordings for Frank and Ernie, settling their disagreement with evidence that establishes that the swans they have seen are not mute swans, but trumpeters.

This is a situation in which we have two arguments: one that shows that the swans are not mute swans, and one that shows that they are trumpeters. We can dress and diagram this second argument as follows.

\begin{tabular}{llc}
\hline Act of arguing & Argument & Mode of arguing \\
\hline Listening to our recording of the swans & Premise $\left(r_{1}\right)$ : Our recording & $\begin{array}{c}\text { Arguing by (non- } \\
\text { verbal) sound }\end{array}$ \\
$\begin{array}{c}\text { Listening to the ornithology recording of } \\
\text { Trumpeter swans }\end{array}$ & Premise $\left(r_{3}\right)$ : Lab recording & $\begin{array}{c}\text { Arguing by (non- } \\
\text { verbal) sound }\end{array}$ \\
$\begin{array}{ll}\text { Claim that 'The swans are trumpeters' } \\
\text { Conclusion }(t) \text { : The swans are } \\
\text { trumpeters }\end{array}$ & \begin{tabular}{l} 
Verbal claim \\
\hline
\end{tabular} \\
\hline
\end{tabular}




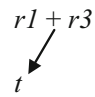

In this case, the building blocks we use to construct our final argument include words and sentences, but the key evidence is provided by the recordings we play for Frank and Ernie. In the process we employ a mode that we may call arguing by nonverbal sound.

The decision to define modes of arguing in terms of the ingredients arguers use in constructing arguments suggests that there are modes of arguing that employ visuals of many different sorts (diagrams, graphs, photographs, videos, paintings, observation, etc.), tactile sensations, musical notes, non-verbal sounds, and a wide variety of other non-verbal elements. In such a context, 'sub modes' can be understood as subsets of more broadly defined modes. It will take a great deal more time and study to establish what typology of modes and sub modes are the best basis for a comprehensive account of real life argument, especially as the importance of a particular mode or sub mode may fluctuate. In the age of print, an overwhelming emphasis on the verbal mode of arguing may have been adequate and appropriate. In a digital age, we need a set of modes that accommodates digital communication and the ease with which it embraces images and sounds of all sorts. In a future age which employs radically new ways of arguing we have not imagined, the relative significance of particular modes may change in the context of this new reality.

\section{Gilbert's Modes}

The account of modes I propose pushes argumentation theory in the same general direction as social semiotics, which uses the term multimodality "to highlight the importance of taking into account semiotics other than language-in-use, such as image, music, gesture, and so on... In general terms, the trend towards a multimodal appreciation of meaning making centers around two issues: first, the de-centering of language as the favored means of meaning making; and second, the re-visiting and blurring of the traditional boundaries between the roles allocated to language, image, page layout, document design, and so on." (Iedema 2003, 33) But social semiotics is not a discipline that situates its account of multimodality within a theory of argumentation. To find that, one must turn to Gilbert. In response to traditional accounts of argument, his theory maintains "that arguments can be categorized, in whole or part, by not one, but four distinct identifiable modes. These modes are, in addition to (1) the logical..., (2) the emotional, which relates to the realm of feelings, (3) the visceral, which stems from the arena of the physical, and (4) the kisceral (from the Japanese term ki meaning energy), which covers the intuitive and nonsensory areas" $(1997,79)$.

One theme that motivates Gilbert's discussion is the conviction that we should recognize a much broader range of arguments than those acknowledged in traditional theories of argument. In particular, he seeks to expand argument beyond 
linguistic attempts to settle disagreement, recognizing acts of arguing constructed from non-verbal utterances, visual cues, actions, images and performances. In the case of his third mode, the visceral, physical action is a $\mathrm{KC}$ of an argument. Consider a situation in which one of my sons (Scott) bragged to a visitor that he was able to juggle four balls in the air. When the visitor dismissed him with a skeptical remark, he took four oranges from a bowl on the table and juggled them in front of us. In this demonstration we have all the hallmarks of good argument: disagreement, an attempt to resolve it with evidence, and an obvious (if implicit) conclusion that cannot be reasonably denied.

In this case, we can dress the argument as follows.

\begin{tabular}{lll}
\hline Act of arguing & Argument & Mode of arguing \\
\hline $\begin{array}{l}\text { Scott juggles the four } \\
\text { oranges }\end{array}$ & Premise (j): The juggling & Visual (performance) \\
& $\begin{array}{l}\text { Conclusion }(c) \text { : The visitor is wrong (Scott } \\
\text { can juggle) }\end{array}$ & $\begin{array}{l}\text { Enthymeme (implicit in the } \\
\text { context) }\end{array}$ \\
\hline
\end{tabular}

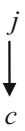

In this $\mathrm{KC}$ table I have classified what happens in the act of arguing as an instance of the visual mode of arguing because it is what one sees that establishes the conclusion. One might alternatively classify it as an instance of Gilbert's visceral mode.

The overlap between Gilbert's approach to modes and the one suggested here is significant, but there are differences of note. One is Gilbert's much broader account of arguing, which understands an argument as any attempt to overcome disagreement. In contrast, I have retained a conception of argument which is more closely tied to standard accounts of arguing, making arguments collections of premises and conclusions which are an attempt to provide rational evidence for some point of view. It goes without saying that it may be possible to resolve a disagreement in some other way-by hitting someone or kissing them or making a joke or distracting them in some way-but I have not categorized this as argument. To this extent, my account of modes maintains a conception of argument which is closer to traditional accounts.

Putting aside issues of definition, my account defines modes of arguing in a more straightforward way than Gilbert does. To see if an act of arguing is an instance of a particular mode it is enough to check whether it is built from the ingredients that define the mode. For a number of reasons, Gilbert's modes are more difficult to discern. In some cases, this is because they are characterized by vague definitions and intuitions that make it difficult to identify and distinguish instances of a mode. The kisceral mode is, for example, defined in terms of 'intuitions' and "energy." This is meant to extend the boundaries of argument but it is not entirely clear 
exactly what 'intuitions' means, especially as appeals to intuition may play a role in logical, mathematical and moral arguments. In the case of the visceral mode, it is difficult to know how we should distinguish between instances of it and instances of for many physical actions can be understood as expressions of emotion.

More problematically, Gilbert's modes have normative dimensions. An argument is, for example, an instance of the 'logical' mode when it is properly judged by the traditional norms of logic. As he puts it, this category 'is intended to indicate not merely a respect for orderliness of presentation, but also a subscription to a certain set of beliefs about evidence and sources of information.' (1997, 78) Judged from this point of view, a logical argument is one that is appropriately judged using the standards of logic; an emotional argument is one that is properly assessed by emotional standards; and so on. In this way, Gilbert's modes introduce alternative standards for assessing argument.

I believe that there is something to be learned from Gilbert's attempt to broaden argument evaluation, but that it is better to separate accounts of modes and accounts of argument assessment. At the very least, failing to do so greatly complicates the attempt to categorize acts of arguing in terms of modes. Using Gilbert's theory, a decision that an argument is an instance of a mode other than the logical mode requires, for example, not only the judgment that it has a different form than arguments as they are traditionally conceived, but also the judgment that it should be evaluated using alternative standards of assessment. In contrast, the account of modes proposed here leaves open the question whether instances of different modes must be judged on the basis of different criteria of assessment. In the case of most of the examples given here, it appears that no different criteria are required.

\section{Visual Arguing: Modes and Sub Modes}

In the remainder of this essay I want to illustrate the proposed account of modes by considering specific modes. I will define the mode of visual arguing as arguing which employs non-verbal visual elements (written arguments are made up of visual signs, but they are not instances of the visual mode, which recognizes arguments constructed from other kinds of visuals). A scientific example is referred to in the following report from the Science section of Wired, which claims that the Mars Phoenix Rover has delivered evidence that resolves longstanding debates over the question whether there is ice on Mars:

There is water ice on Mars within reach of the Mars Phoenix Lander, NASA scientists announced Thursday. Photographic evidence settles the debate over the nature of the white material seen in photographs sent back by the craft. As seen in [the photographs]..., chunks of the ice sublimed (changed directly from solid to gas) over the course of four days, after the lander's digging 
exposed them. 'It must be ice,' said the Phoenix Lander's lead investigator, Peter Smith. 'These little clumps [we see] completely disappearing over the course of a few days, that is perfect evidence that it's ice.' (Madrigal 2008)

Leaving aside a detailed account of all the theorizing behind the argument referred to, we can summarize Peter Smith's argument as follows.

\begin{tabular}{lll}
\hline $\begin{array}{l}\text { Act of arguing } \\
\begin{array}{l}\text { Reference to the portions of the Rover photographs } \\
\text { showing the disappearing 'clumps of ice' }\end{array}\end{array}$ & $\begin{array}{c}\text { Argument } \\
\text { Premises }\left(p_{1} \ldots p_{x}\right) \text { : Details of } \\
\text { the photographs }\end{array}$ & $\begin{array}{c}\text { Visual } \\
\text { (sequential } \\
\text { photographs) }\end{array}$ \\
An explanation of this change & $\begin{array}{l}\text { Premise }(i) \text { : They must be } \\
\text { disappearing because they } \\
\text { are ice }\end{array}$ & Verbal claim \\
Claim that "There is water ice on Mars" & $\begin{array}{c}\text { Conclusion }(w) \text { There is } \\
\text { water ice on Mars }\end{array}$ & Verbal claim \\
\hline
\end{tabular}

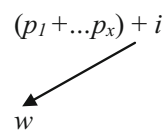

The full reasoning that leads to this inference is in many ways a paradigm example of a multimodal argument, insofar as it combines verbal and visual modes of arguing. The important point is that both are essential to the argument and that it is the presentation of the photographs which is the key move in the argument.

In any comprehensive attempt to understand the visual mode of arguing it will be important to distinguish sub modes it encompasses, for different sub modes will require different strategies of interpretation. In many, perhaps most, situations, photography is properly interpreted as an attempt to present an exact likeness of what is photographed. Not so in many genres of illustration, which invite creativity that may purposely distort. Consider the following Paul Szep cartoon (below), published in 1968, when US President Lyndon B. Johnson was being promoted as a candidate for a second term of office. The caption underneath it was Johnson's comment that: "We are not going to send American boys 9,000 or 10,000 miles to do what Asian boys ought to be doing for themselves."

In this case, the act of arguing which is the cartoon needs to be understood in the context of President Johnson's promise that he would not send American troops to Vietnam (quoted in the caption of the cartoon). In part, the cartoon is a rhetorical exercise designed to ridicule Johnson and diminish his esteem. But it is not just rhetorical, for it forwards evidence which is supposed to show that Johnson is not an appropriate candidate for a second term in the White House. 


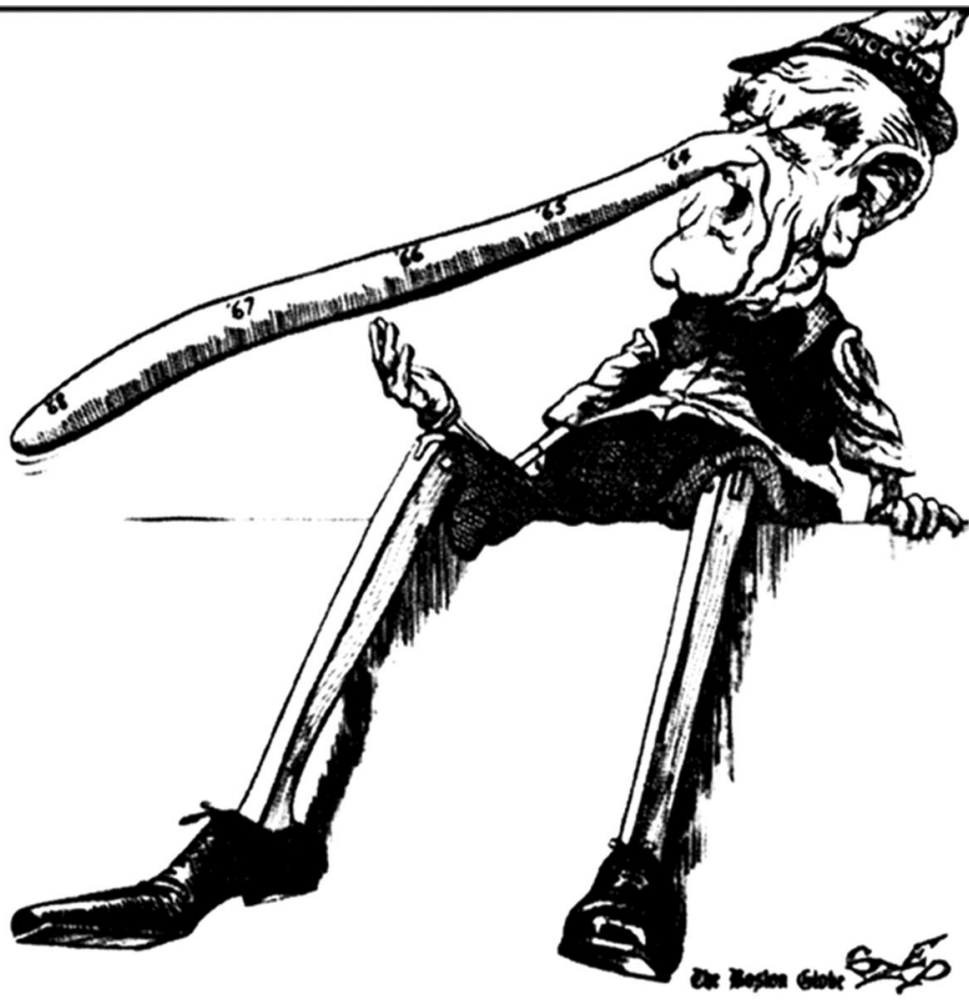

We can dress the argument as follows.

Act of arguing

Argument

Mode of

arguing

The drawing of the calibrations marking the growth of Johnson's nose in 1964-1968

Premises $\left(s_{1} \ldots s_{5}\right)$ : The details in the drawing of the nose

Visual

Quote of Johnson saying "We are not going to send American Boys..."

Premise (n): Johnson said he was not going to send 'American Boys' to Vietnam

(caricature)

Verbal claim (caricature)

Depiction of Johnson as a lying Pinnochio

Sub Conclusion $(l)$ : Johnson is as depicted (ridiculous, a liar, etc.)

Visual

(caricature)

Implicit conclusion $(r)$ : Johnson should not be re-elected

Enthymeme 


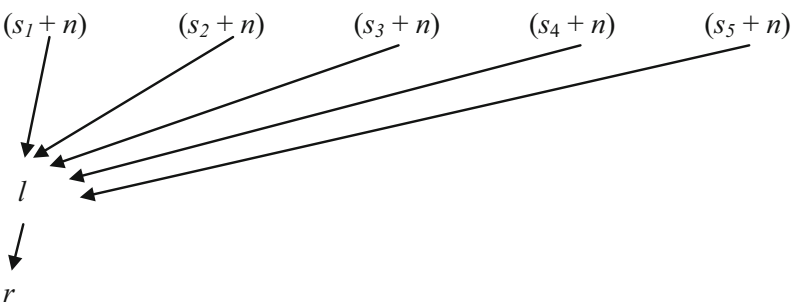

In order to properly interpret this act of arguing we must recognize that depicting someone as a lying Pinnochio (with an extending nose) is a standard visual motif that portrays them as a liar. In assessing the argument, we would need to assess the inferences from $(s+n)$ to the conclusion - i.e. the suggestion that we can infer that a politician is (like Pinnochio) an irresponsible liar if they do not keep earlier campaign promises (something that is not as obvious as Szep's cartoon suggests). In the present context, it is enough to note that the images we find within political cartoons are a sub species of visual arguing in which visual depictions are not meant to be understood literally, but metaphorically.

In other visual sub modes, visual representations may be symbolic. Consider the German post card illustration I have reproduced below. Created in the early 1930s, it-and 100 s of

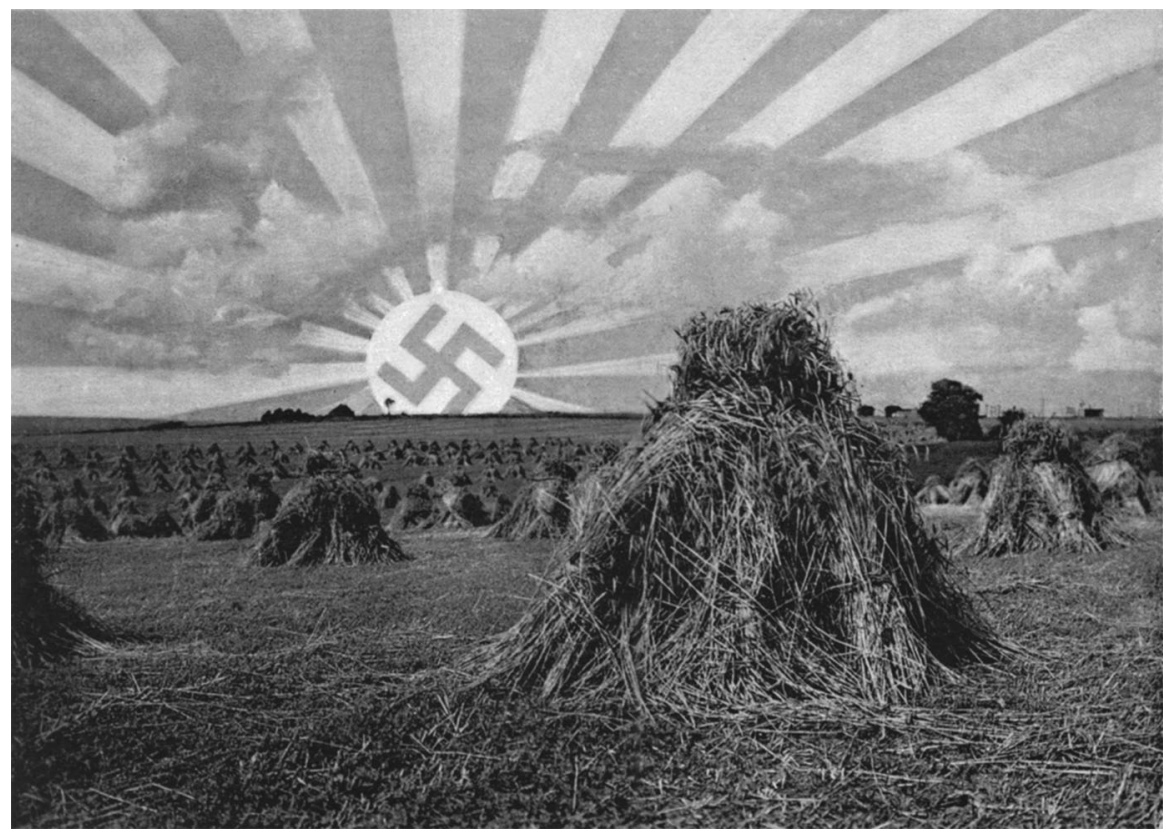

other Nazi postcards like it—were part of a coordinated campaign to convince voters that they should support the Nazi party in national elections. Here the disagreement is over whom one should elect to government. To understand the argument, we must recognize (intuitively or by studying the history of illustration), that a rising sun is a standard way for illustrators to refer to the future (see Roque 2010). In the example included here, the two key components of the photograph are a sun emblazoned with a 
swastika and a wheat field, which suggest that a Nazi future will bring food and abundance (a matter of note in a time of food shortages). In the post card, the message is reinforced verbally, with the printed caption Freiheit und Brot durch Adolf Hitler ("Freedom and Bread under Adolf Hitler"). We might dress and diagram the act of arguing that is the post card as follows.

\begin{tabular}{llc}
\hline Act of arguing & Argument & Mode of arguing \\
\hline $\begin{array}{l}\text { Depiction of a rising swastika sun over } \\
\text { a field of wheat }\end{array}$ & $\begin{array}{c}\text { Premise }(p) \text { : A Nazi future will bring } \\
\text { bread and prosperity. }\end{array}$ & $\begin{array}{c}\text { Visual (photograph } \\
\text { with symbol) }\end{array}$ \\
$\begin{array}{l}\text { Claim (printed) that Hitler will bring } \\
\text { 'Freedom and Bread' }\end{array}$ & $\begin{array}{c}\text { Premise }(h) \text { : Hitler will bring 'Freedom } \\
\text { and Bread' }\end{array}$ & Verbal claim \\
& Conclusion $(n)$ : You should vote Nazi & Implicit conclusion \\
\hline
\end{tabular}

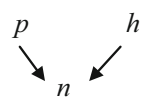

In an attempt to demonstrate the great variety of ways in which the mode of visual arguing can manifest itself, I will complete this overview with a photo chosen as one of the 1983 "Pictures of the Year" by the Reynolds Journalism Institute (Damaske 1983). It is a photograph of a trial in Pinellas County, Florida. In the case in question the issue was whether an exotic dancer working in a nightclub displayed herself in a way that was illegal while she was dancing. What one sees in the photograph is the dancer defending herself by trying to demonstrate to the judge that she could not have exposed herself in the way alleged because her underwear made it impossible to do so. In this situation, this act of undressing is an act of arguing, the dancer trying to prove that she is not guilty of the crime she is accused of by providing evidence that this was impossible.

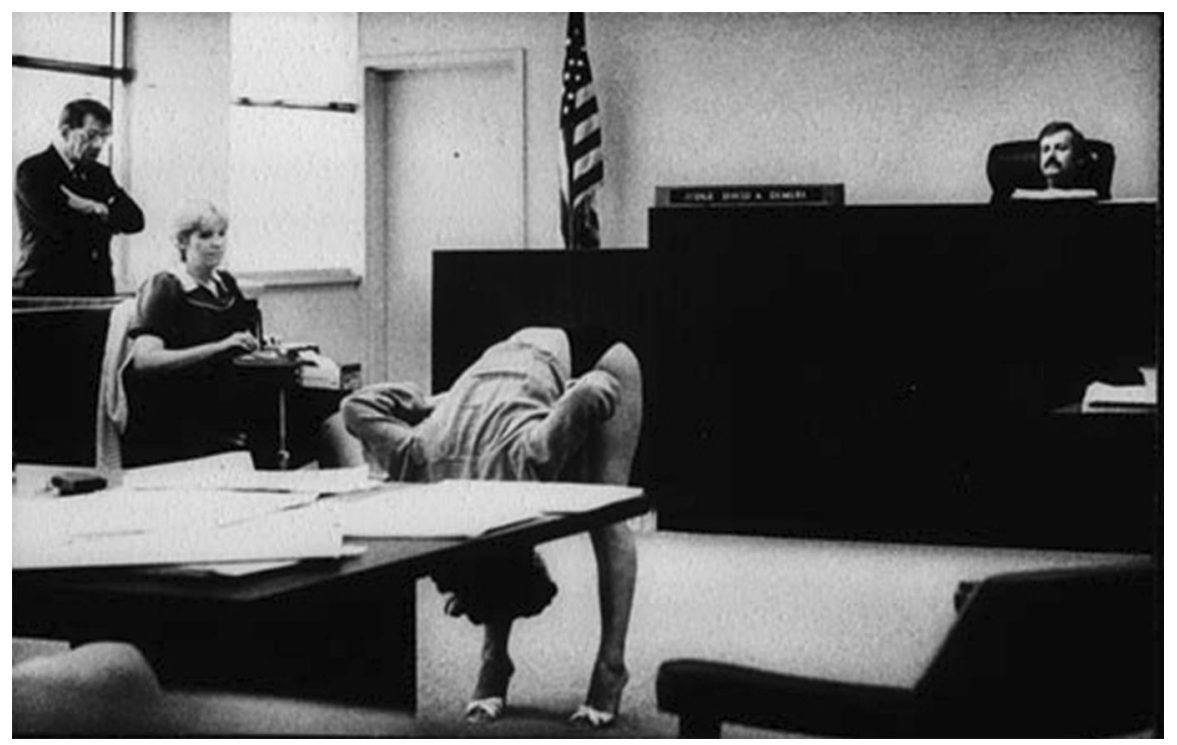


We can dress this act of arguing as follows.

\begin{tabular}{llc}
\hline Act of arguing & Argument & Mode of arguing \\
\hline Demonstration in the court & $\begin{array}{c}\text { Premise }(d) \text { : What the } \\
\text { demonstration displays }\end{array}$ & $\begin{array}{c}\text { Visual } \\
\text { (demonstration) }\end{array}$ \\
$\begin{array}{c}\text { Claim that 'My underwear makes it impossible to } \\
\text { display myself in the way alleged' }\end{array}$ & $\begin{array}{c}\text { Sub conclusion }(g) \text { : My } \\
\text { underwear... alleged } \\
\text { Claim that 'I cannot have done what is alleged' } \\
\text { Main conclusion }(a) \text { : I cannot } \\
\text { have done what is alleged }\end{array}$ & Verbal claim \\
\hline
\end{tabular}

$\stackrel{d}{\downarrow}$

These are only a few instances of the visual mode of arguing. In presenting them I have tried to show, not only that there is a visual mode of arguing (i.e. arguing in which arguers build arguments out of non-verbal visual elements), but that there are a many different ways to argue with non-verbal visual phenomenon. I have no definitive typology to suggest here, but these differences suggest that we need to distinguish between different sub modes that are included within the broader mode of visual arguing. Like the broader mode, they are best defined as acts of argument that are built from different kinds of ingredients-which in this case implies different kinds of visual elements. One might, for example, define sub modes that include acts of arguing that use diagrams, graphs, video, time lapse photography, X-rays, magnetic resonance imaging, oil painting, electron microscope images, and so on and so forth. In dressing and assessing arguments, it will be important to distinguish between many of these different sub modes because they may require different strategies of interpretation. If we classify a move in an argument as an instance of the sub mode "gesture", for example, then a plausible interpretation of it must be founded on a detailed knowledge of gestures, their meaning, and how they work in argument.

\section{Beyond the Visual: Two Ways}

The proposed account of modes defines them in terms of the ingredients used in constructing arguments. In the case of the mode of visual arguing, arguers construct acts of arguing that employ (non-verbal) visuals. One way to extend our set of modes is by expanding it to include arguing which employs other kinds of ingredients. In keeping with this, we might speak of olfactory, tactile, savory, and auditory modes of arguing in which arguers utilize instances of smell, touch, taste and (non-verbal) sound to provide evidence for some conclusion. Two of the arguments we have already noted-one invoking the taste of a wine, the other the songs of different species of swans-illustrate this possibility.

In the present context it is enough to note that there are many other possibilities. Smell is, to take one example, a sense that very frequently functions as a vehicle for 
inference (see Synnott 1991) and may, in the case of a disagreement, provide reasonable evidence for the conclusion that someone is barbequing steak; that the house is on fire; that someone has been smoking tobacco or marijuana; or that someone who wears a distinct perfume has just walked by. The formal use of smell as a basis for inferences that may decide between competing theses is found in medical diagnosis, in which smell plays an established, though sometimes unrecognized, role (Smith et al. 1982).

A second way to expand our set of modes is by subdividing modes of arguing into sub modes. I have already tried to illustrate some possibilities in the case of visual arguing, which encompasses an enormous range of visual phenomena (everything from drawing to painting to videos to photography to sculpture to theatrical performance...). One might, for example, follow the lead of Dickinson et al. (2010), and identify memorials, monuments and memorial spaces as a mode of arguing. As their work amply illustrates, it is not difficult to find examples that demonstrate the argumentative function of such spaces (examples include the Holocaust Museum in New York; the Memorial to the Murdered Jews of Europe in Berlin; and the Rajiv Gandhi Memorial in Chennai).

One question raised by the possibility of sub modes is the question whether we should distinguish between different species of verbal argument. We can, for example, distinguish between an oral and a written/printed mode of verbal arguing. The ingredients of the former are spoken words while the ingredients of the latter are written words. The latter is the form of argument which has traditionally been granted primacy (taking the written/printed word as the ultimate vehicle for careful argument) but the former bears some attention as a unique sub mode, for it is frequently dependent on aspects of spoken communication which have no exact equivalent in print (see Kišiček 2015). To take some examples, intonation, emphasis and other prosodic elements play an essential role in determining when spoken sentences are statements or questions and have one of a variety of different meetings. Imagine a situation in which I say that someone is Croatian and back this standpoint with the claim that she has a Croatian accent and is a friend of the famous Croatian linguist, Ivo Skaric. If I need to back this first claim, I may say 'She said this:' and play you a recording of a message she has left on my phone.

In this case we can dress my argument as follows.

\begin{tabular}{|c|c|c|}
\hline Act of arguing & Argument & Mode of arguing \\
\hline My use of the phone message & $\begin{array}{l}\text { Premise }(r) \text { : What we hear on the } \\
\text { recording }\end{array}$ & $\begin{array}{l}\text { Arguing by oral } \\
\text { claim }\end{array}$ \\
\hline $\begin{array}{l}\text { Claim that 'She has a Croatian } \\
\text { accent' }\end{array}$ & $\begin{array}{l}\text { Sub conclusion }(a) \text { : She has a Croatian } \\
\text { accent }\end{array}$ & Verbal claim \\
\hline $\begin{array}{l}\text { Claim that 'She is a friend of Ivo } \\
\text { Skaric' }\end{array}$ & Premise $(f)$ : She is a friend of Ivo Skaric & Verbal claim \\
\hline Claim that 'She is Croatian' & Conclusion $(d)$ : She is Croatian & Verbal claim \\
\hline
\end{tabular}




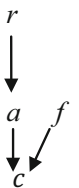

Here the ingredients of the audio recording $r$ are words, but it is important that I have indicated the mode of arguing as oral because pronunciation and other prosodic elements are key ingredients of the evidence put forward. In a case such as this, a purely written account of these words would miss the point, and is not the building block I use to try and create a compelling argument.

In other cases of oral argument, pronunciation, enunciation, pause, prosody, volume, stress and accent may carry significant argumentative meaning. One might in view of this develop an account of an oral mode of arguing which recognizes these elements as important ingredients of argument. It goes without saying that one might move in the other direction as well, recognizing a sub mode of verbal arguing in print which is characterized by the features of the written word.

\section{Argument by Experience}

The proposed account of modes greatly expands what counts as argument. In doing so it provides some grounding for an argumentation theory that can recognize, identify and assess many kinds of argument that it has traditionally ignored. I want to illustrate what this means in practice with a way of arguing I will name 'arguing by experience'. I am not proposing this form of arguing as a mode of arguing, but as a genre of argument that combines modes as I have explained them. One might similarly talk of political cartoons as a genre of argument that typically combines a visual representation and a verbal comment (i.e. visual and verbal modes of arguing), or of documentary film as a genre of argument that combines a great many modes of arguing (e.g., visual, verbal and musical modes of arguing).

An example may illustrate argument by experience. Imagine a trip to Shanghai organized by a host determined to prove to European visitors that it is one of the great cities of the world. With this in mind, he consciously organizes an itinerary to provide evidence that will convince them of this claim. It includes a visit to the towering skyscrapers of the Financial District (towers that themselves make a multimodal statement about the wealth, power and prestige); a cruise along the Huangpu River; a stroll along Zhongshan Road; a performance at the Acrobat Dome; high end shopping in Xintiandi; and so on and so forth. Considered from the point of view of argument, this turns the visit to Shanghai into an attempt to convince the visitors that Shanghai is one of the world's great cities by constructing a complex, multimodal argument.

Above all else, it would be a mistake to think that the experiences this visit encompasses are argumentatively neutral. They are, on the contrary, experiences 
which have been very carefully designed to provide evidence for the conclusion that Shanghai is a remarkable city (as remarkable as other great cities of the world). The exact details of the argument will depend on the specifics of the visit, but we might in general understand this extended act of arguing as a series of sub arguments that employ different modes of arguing that establish that Shanghai is remarkable from the point of view of food, restaurants, architecture, entertainment, and so on and so forth. This is an example of arguing by experience that combines arguing by a great variety of modes (visual, taste, and so on and so forth). A theory of modes is an important development in argumentation theory because it allows us to recognize, dress and assess arguing of this sort. It is especially important to do so given that the multimodal nature of arguing by experience makes it an extremely powerful means of arguing (one finds a partial attempt to capture its power in television, which immerses the viewer in a multi-faceted experience).

\section{Where to from Here?}

In this paper I have tried to develop an account of modes of arguing that places them squarely within the realm of argumentation theory. In doing so, I have introduced a method for dressing arguments that can be used in the analysis of multimodal acts of arguing. I have illustrated $\mathrm{KC}$ tables with a variety of examples that recognize nonverbal elements of arguing as premises and conclusions in arguments. I have purposely designed the tables so that they can identify such elements without attempting to translate such elements into words and sentences (leaving open the question whether they are propositional or not).

Using KC tables, I have argued for a conception of modes that defines them in terms of the significant ingredients from which arguments are constructed. I have tried to show that the latter may include a great many non-verbal building blocks for argument. In the case of modes like the mode of visual argument, this may include sub modes that employ subsets of the ingredients that define the broader mode. In the course of my discussion, I have argued that modes of arguing can introduce a new element into argument analysis, allowing for the analysis of arguments that employ pictures, tastes, graphs, diagrams, acts of seeing, objet d'art, smells, and so on and so forth. Doing so extends the reach of argumentation theory to a much broader realm of arguing.

I want to end this essay by noting that the proposed account of modes of arguing is not an endpoint so much as a step toward further research. In the investigation of particular modes and sub modes it will be important to resolve the questions of meaning and interpretation they raise. This will require more detailed studies of the ways in which we should understand and analyze graphs, video clips, gestures, smells, tattoos, caricatures, music, and other non-verbal ingredients of argument, especially as the use of the different ingredients that characterize different modes tend to be associated with different norms and expectations. From a broader point of view, my account raises the question what set of modes (and/or sub modes) is the 
best basis for a truly comprehensive account of argument—or best for a particular purpose.

Perhaps the most important area for further investigation is multimodality and its implications for argument evaluation. In this essay I have not tried to address this issue. In the present context it may be helpful to say that attempts to do so may usefully follow traditional accounts of argument and distinguish between the evaluation of an argument's premises and the evaluation of the inference from its premises to the conclusion. In assessing premises, it is now common to ask whether an argument's premises are rationally acceptable (rather than true). In the case of multimodal arguments, we might similarly ask whether non-verbal premises are rationally acceptable, though doing so raises issues that merit more investigation. Sometimes we describe such elements as true, correct or reliable: or as fake, misleading or deceptive (as when we speak of a 'true' likeness of Aristotle; an unreliable map or an 'olfactory hallucination'). In judging non-verbal premises, the key point is that they are in some cases a reasonable basis for an inference-and in other cases not.

In our first example of multimodal argument, we can imagine circumstances in which my photograph of van Eemeren might be judged rationally unacceptable for a variety of reasons: because it is not a photograph of him (but someone else), because it is a photo of him when he was much younger, because it is a very poor quality photo. In the case of our wine example, the tasting that the argument depends on may also be rationally acceptable or not. Perhaps my palate was not in the right condition for a tasting-because I have been eating strong food or drinking too many other wines. Perhaps the bottle has been open too long and the wine has oxidized or refermented (when California wines bested French vintages in the now famous "Judgment of Paris" competition held in 1976, some French experts argued that the wines had not aged sufficiently to allow a proper tasting).

In the case of inference, multimodal arguments may in some circumstances be much stronger than purely verbal counterparts. If I want to argue that an exotic species (the dodo, the ivory billed woodpecker, etc.) is not extinct, then the strongest evidence I can provide is an actual living specimen. In other cases, verbal and multimodal forms of inference raise similar issues. In an advertisement, someone wearing a white lab coat with a stethoscope around their neck is being presented as a medical doctor. When such a figure proceeds to tell us that a particular kind of medication is superior to alternatives, we are being offered a multimodal appeal to authority. From a logical point of view (i.e. in assessing the reasonableness of such an argument) this appeal poses no special issues for assessment, for a multimodal appeal to authority can be assessed in the same way as a verbal appeal—by asking the critical questions associated with this particular argument scheme (what are the authority's credentials, is this a topic on which authorities agree, ...). Dove (2009) has usefully applied the criteria of arguments from authority to notes on whisky tasting.

In many other cases, multimodal acts of argument can be assessed by applying or extending the methods of evaluation developed in pragma-dialectics, rhetoric, informal logic, and other strands of argumentation theory. In practice this means that one can assess such arguments by identifying them as instances of particular 
fallacies or argument schemes; by considering whether they are rhetorically successful; and so on. Like verbal argumentation, multimodal argumentation can be assessed and considered from the point of view of the rules of critical discussion (or the rules and norms associated with other kinds of dialogue). The question whether there are special cases in which a decision to recognize alternative modes of arguing requires some additions to standard theories of argument assessment is an intriguing one. The discussion of this issue is still in its early stages (see Godden 2013).

It will take time and more study to decide how best to define individual modes; what typology of modes can best explain real life argument; and the standards of assessment instances of different modes require. Here it must suffice to say that a recognition that there are alternative (non-verbal) modes, the general account of modes I have proposed, and the method for dressing multimodal arguments I have suggested can be a basis for the investigation this requires. Beyond this, it must be said that a more detailed and complete theory of multimodal argument is something that must, like fine wine, develop over time.

Acknowledgments I am indebted to colleagues for discussions and criticisms of the various issues and examples mentioned in this paper. In particular, I would like to thank Tony Blair, Jens Kjeldsen, Assimakis Tseronis, Ana Dimiskovska, and especially the anonymous reviewers of this paper. The latter challenged me in a way that forced me to rethink some key aspects of the views I have presented here.

Open Access This article is distributed under the terms of the Creative Commons Attribution License which permits any use, distribution, and reproduction in any medium, provided the original author(s) and the source are credited.

\section{References}

Barceló Aspeitia, Axel Arturo. 2012. Words and images in argumentation. Argumentation 26(3): 355-368.

Birdsell, David, and Leo Groarke. 2007. Outlines of a theory of visual argument. Argumentation and Advocacy 43(2\&3): 103-113.

Blair, J. Anthony. 1996. The possibility and actuality of visual arguments. Argumentation and Advocacy 33(1): 23-39.

Carozza, Linda. 2007. Dissent in the midst of emotional territory. Informal Logic 27(2): 197-210.

Damaske, Jim. 1983. Legal briefs. POYi Archive (item \#12884). http://archive.poyi.org/items/show/ 12884. (Accessed 30 Apr 2014).

Dickinson, Greg, Carole Blair, and Brian Ott. 2010. Places of public memory: The rhetoric of museums and memorials. Tuscaloosa: University of Alabama Press.

Dove, Ian. 2012. Image, evidence, argument. In Topical themes in argumentation theory, ed. Frans. H. van Eemeren, and B. Garssen, 223-238. Amsterdam: Springer.

Dove, Ian. 2009. What do tasting notes tell us? In Whiskey and philosophy: A small batch of spirited ideas, ed. F. Allhoff, and M. Adams, 224-239. New York: Wiley.

Duran, Claudio. 2007. Bi-logic and multi-modal argumentation: Understanding emotional arguments. In Dissensus and the search for common ground, ed. H.V. Hansen, C.W. Tindale, J.A. Blair, R.H. Johnson, and D.M. Godden, 1-9. Windsor: Ontario Society for the Study of Argumentation.

Duran, Claudio. 2010. Bi-logical analysis of arguments in political propaganda: The case of the Chilean Press 1970-1973. In Proceedings of the 7th conference of the International Society for the Study of Argumentation, 359-366. Amsterdam: Sic Sat.

Feteris, Eveline, Leo Groarke, and José Plug. 2011. A pragma-dialectical analysis of the use of topi that are based on common cultural heritage. In Keeping in touch with pragma-dialectics, ed. E. Feteris, B. Garssen, and F. Snoeck Henkemans, 59-75. Amsterdam: John Benjamins. 
Gelang, Marie, and Jens Kjeldsen. 2011. Nonverbal communication as argumentation. In Proceedings of the 7th conference of the International Society for the Study of Argumentation, ed. F.H. van Eemeren, B. Garssen, D. Godden, and G. Mitchell, 567-576. Amsterdam: SicSat.

Gilbert, Michael A. 1994. Multi-modal argumentation. Philosophy of the Social Sciences 24(2): 159-177.

Gilbert, Michael A. 1997. Coalescent argumentation. Mahwah, NJ: Lawrence Erlbaum Associates.

Gilbert, Michael A. 2002. Effing the ineffable: The logocentric fallacy in argumentation. Argumentation 16(1): 21-32.

Gilbert, Michael A. 2004. Emotion, argumentation \& informal logic. Informal Logic 24(3): 245-264.

Godden, David M. 2013. On the norms of visual argument. In Virtues of argument, ed. Dima Mohammed, and Marcin Lewiński. Windsor: Ontario Society for the Study of Argumentation.

Groarke, Leo. 1996. Logic. Art and Argument. Informal Logic 18(2\&3): 116-131.

Groarke, Leo, and Sharon Dewey. 2002. Are musical arguments possible? In Proceedings of the 5th international conference on argumentation, ed. F.H. van Eemeren, J.A. Blair, C.A. Willard, and F. Snoeck Henkemans, 419-423. Amsterdam: Sic Sat.

Iedema, Rick. 2003. Multimodality, resemiotization: Extending the analysis of discourse as multisemiotic practice. Visual Communication 2(1): 29-57.

Kjeldsen, Jens. 2007. Visual argumentation in Scandinavian political advertising. A cognitive, contextual and reception oriented approach. Argumentation and Advocacy 43: 124-132.

Kišiček, Gabrijela. 2015. The role of paralinguistic features in the analysis of multimodal argumentation. In Proceedings of the 8th conference of the International Society for the Study of Argumentation (forthcoming).

Kress, Gunther. 2010. Multimodality: A social semiotic approach to contemporary communication. New York: Routledge.

Kress, Gunther, and Theo Van Leeuwen. 1996. Reading images: The grammar of visual design. London: Routledge.

Langsdorf, Lenore. 2003. How narrative argumentation works: An analysis of argumentation aimed at reconsidering goals. In Anyone who has a view: Theoretical contributions to the study of argumentation, ed. F.H. van Eemeren, J.A. Blair, C.A. Willard, and F. Snoeck Henkemans, 337-346. Amsterdam: Kluwer.

Madrigal, Alexis. 2008. Mars phoenix tweets: "We have ICE!" Wired Magazine. http://www.wired.com/ 2008/06/mars-phoenix-tw/. (Accessed 11 May 2014).

O'Keefe, Daniel J. 1977. Two concepts of argument. The Journal of American Forensic Association 13(Winter): 121-129.

Pinto, Robert C. 2001. Argument, inference and dialectic: Collected papers on informal logic. Dordrecht: Kluwer.

Roque, Georges. 2010. Expresiones y Modalidades del Futuro en la Imagen Fija. In El futuro: XXXI Coloquio internacional de historia del arte, ed. Alberto Dallal, 17-35. Oaxaca Mexico: Universidad Nacional Autónoma de México, Instituto de investigaciones Estéticas.

Roque, Georges. 2012. Visual argumentation: A further reappraisal. In Topical themes in argumentation theory, ed. F.H. van Eemeren, and B. Garssen, 273-290. Amsterdam: Springer.

Slade, Cristina. 2002. The real thing: Doing philosophy with the media. New York: Peter Lang.

Smith, Michele, Leon G. Smith, and Benjamin Levinson. 1982. The use of smell in differential diagnosis. The Lancet 320(8313): 1452-1453.

Synnott, Anthony. 1991. A sociology of smell. Canadian Review of Sociology and Anthropology $28: 437$.

Tseronis, Assimakis. 2013. Argumentative functions of visuals: Beyond claiming and justifying. In Virtues of argument, ed. Dima Mohammed, and Marcin Lewiński. Windsor: Ontario Society for the Study of Argumentation.

van den Hoven, Paul. 2012. Getting your ad banned to bring the message home? A rhetorical analysis of an ad on the US national debt. Informal Logic 32(4): 381-402.

Woods, John. 1995. Fearful symmetry. In Fallacies: Classical and contemporary readings, ed. Hans V. Hansen, and Robert C. Pinto, 181-193. University Park, PA: Pennsylvania State University Press. 